\title{
Evidence towards a thermal lag in the response of Kårsaglaciären, northern Sweden, to climate change
}

\author{
David M. RIPPIN, ${ }^{1}$ Jonathan L. CARRIVICK, ${ }^{2}$ Christopher WILLIAMS ${ }^{2}$ \\ ${ }^{1}$ Environment Department, University of York, Heslington, York YO10 5DD, UK \\ E-mail: david.rippin@york.ac.uk \\ ${ }^{2}$ School of Geography, University of Leeds, Leeds LS2 9JT, UK
}

\begin{abstract}
Recent topographical and ground-penetrating radar (GPR) surveys of Kårsaglaciären, which is a small $\left(<1 \mathbf{k m}^{2}\right)$ and thin $(<56 \mathrm{~m})$ mountain glacier in Arctic Sweden, show that there are small areas of temperate ice in the lowermost part of the glacier. This is curious because we would expect such a small and thin glacier to have a fully cold ablation zone. Specifically, with our analyses of present glacier geometry and thickness and of the prevailing climate, we are unable to explain the presence of temperate ice within the snout of Kårsaglaciären using prevailing models of glacier thermal structure. This leads us to suggest that the presence of temperate ice within Kårsaglaciären is a remnant of a previous polythermal state that existed when the glacier was larger and thicker. Kårsaglaciären is thus out of synch with current geometry and climate and is exhibiting a 'thermal lag'. We propose that, with time, Kårsaglaciären's ablation zone and perhaps the entire glacier may well become fully cold as the temperate zone shrinks further. We anticipate that such a thermal lag is likely to be present within other Arctic glaciers. A thermal lag and an evolution to a fully cold thermal state have significant implications for the dynamic behaviour of small Arctic glaciers and for meltwater production from them.
\end{abstract}

\section{INTRODUCTION AND RATIONALE}

Arctic glaciers and ice caps presently contribute $\sim 0.13 \mathrm{~mm} \mathrm{a}^{-1}$, or $>30 \%$, of the sea-level rise from ice masses outside Antarctica and Greenland (Dowdeswell and others, 1997). The magnitude of the contribution from Arctic glaciers is perhaps surprising since $>99 \%$ of all of the Earth's water that is held up in glacier ice is found in Antarctica and Greenland (Radić and Hock, 2011). However, the disproportionate contribution can be explained by considering that many Arctic glaciers are small and thus their mass balance can respond to climate changes much more rapidly than the major ice sheets (Prowse, 1990; Dowdeswell and others, 1997; Munro, 2000; Bingham and others, 2006). Such small glaciers are widespread in the Arctic: the World Glacier Inventory (WGI) indicates that of $>7400$ glaciers in 2009 located within the Arctic (i.e. above $66^{\circ} 33^{\prime} \mathrm{N}$ ), $64.2 \%$ were $\leq 2 \mathrm{~km}^{2}$ in area, while $77.9 \%$ were $\leq 5 \mathrm{~km}^{2}$ in area (http:// nsidc.org/data/g01130.html). The sensitivity of small Arctic glaciers to climatic forcings makes them very important components of the cryosphere, particularly as climate change is forecast to proceed most rapidly in the Arctic (Bates and others, 2008). They have additional significance because shrinkage of Arctic glaciers has significant impacts on local stream hydrology and ecology and has direct consequences for water resource management (Arendt and others, 2002; Raper and Braithwaite, 2006).

Many Arctic glaciers are commonly assumed to be polythermal (Holmlund and Eriksson, 1989; Aschwanden and Blatter, 2005; cf. Hutter and others, 1988; Blatter and Hutter, 1991). A polythermal glacier state means that both warm and cold ice coexist. Warm (or temperate) ice is at or very close to the pressure-melting point (pmp), whereas cold ice is well below the pmp. This distinction enables whole glaciers to also be classified as warm/temperate or cold (when they consist entirely of warm or cold ice, respectively), or indeed polythermal where both types of ice exist in a single glacier. However, the nature of the polythermal structure can also vary depending on the balance between surface and subsurface processes (Blatter and Hutter, 1991; Pettersson, 2004; Benn and Evans, 2010).

Polythermal glaciers can range from being almost entirely cold, with just a small temperate basal region (type A according to the classification of Pettersson, 2004), to almost entirely temperate, with just a small region of cold surface ice (type $\mathrm{F}$ according to the classification of Pettersson, 2004), with a continuum of other intermediate structures in between. Polythermal glaciers are particularly well studied in Svalbard (Schytt, 1969; Björnsson and others, 1996; Sund and Eiken, 2004) and have also been documented in Sweden with the most well known being Storglaciären (Holmlund and Eriksson, 1989; Pettersson and others, 2003, 2004; Gusmeroli and others, 2010). Storglaciären is an example of a polythermal glacier that is largely temperate (predominantly warm polythermal glacier) with only a cold surface layer overlying otherwise temperate ice in the ablation area and fully temperate ice in the accumulation area (Pettersson and others, 2007; type E according to the classification of Pettersson, 2004). The structure here arises because of the existence of porous firn in the accumulation area which can become water-saturated as a result of spring/ summer snowmelt. Subsequent refreezing of this water at the firn-ice boundary produces substantial amounts of heat which leads to the formation of temperate ice (Gusmeroli and others, 2010).

Elsewhere, in predominantly cold polythermal glaciers, the structure consists primarily of cold ice with only a temperate basal layer (e.g. Bingham and others, 2006; type A according to Pettersson, 2004). In this latter type, temperate ice may arise due to strain heating while ice thickness can also play a very significant role in maintaining temperate ice in the ablation area. This is because: (1) strain heating is greater under thicker ice; (2) thicker ice reduces the pmp; and (3) thicker ice has an insulating effect, keeping ice at depth warmer (Bennett and Glasser, 2009), i.e. in the 


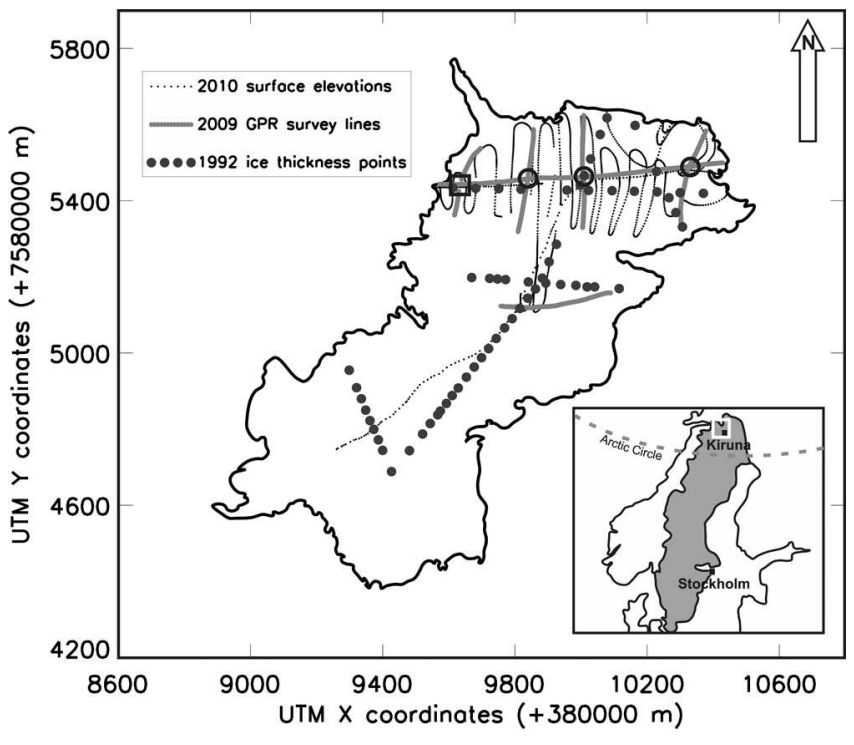

Fig. 1. Survey tracks across Kårsaglaciären, northern Sweden. The three black rings show the locations of 2009 crossover locations. The black square shows the fourth crossover location where there was disagreement in bed elevation. Flow direction is from the bottom left to the top right of the image. The inset shows the location of Kårsaglaciären in Sweden, close to the town of Kiruna.

Arctic, cold winter temperatures can penetrate deep into a glacier, reducing ice temperature (Sverdrup, 1935; Paterson, 1994; Rippin, 2002). In thicker Arctic glaciers this 'winter cold wave' does not penetrate through the full thickness of the glacier and so deeper ice is likely to remain temperate, whereas in very thin glaciers the cold wave might even reach the bed (Björnsson and others, 1996).

These conditions lead us to propose that in Arctic locations, glaciers that are small and thin are likely to consist entirely of ice that is below the pmp. This is supported by Murray and others $(2000$, p. 13,501) who stated that 'glacier thermal regime is strongly influenced by ice thickness' and suggested that, in Svalbard, glaciers less than $\sim 100 \mathrm{~m}$ thick are cold throughout. Such a cold thermal state has important implications for glacier hydrology and dynamics because cold ice theoretically contains no water and thus has a dynamical regime characterized as slow, inactive and consequently with minimal geomorphological impact (cf. Fischer and Clarke, 2001; Waller, 2001). Similarly, the presence of a cold ablation zone in front of a temperate accumulation zone also has implications for ice dynamics and hydrology (cf. Rippin, 2002; Rippin and others, 2005; Bingham and others, 2006). This study therefore aims to test the hypothesis that a small thin Arctic glacier will possess an ablation area that is composed entirely of homogeneous cold ice.

\section{FIELD SITE}

Kårsaglaciären is located in Arctic Sweden at the head of Kårsavagge $\sim 25 \mathrm{~km}$ west of Abisko in northern Sweden (Fig. 1). The glacier ranges in elevation from $\sim 1000$ to $\sim 1500 \mathrm{~m}$ a.s.l. and thus has an arctic climate, despite being situated within a region generally characterized as subarctic. Upper Kårsavagge $\left(68^{\circ} 21^{\prime} \mathrm{N}, 18^{\circ} 49^{\prime} \mathrm{E}\right)$ includes Kårsaglaciären, which is a $\sim 1 \mathrm{~km}^{2}$ glacier, and several cirques that are now without permanent glacier ice (Fig. 1).
Our choice of this glacier among the many small and climatically sensitive glaciers in northern Scandinavia (Carrivick and Brewer, 2004) is motivated by a secondary aim to establish the present-day geometry and state of Kårsaglaciären. Kårsaglaciären has been studied intermittently for over 100 years (e.g. Svenonius, 1890, 1910; Ahlmann and Tryselius, 1929; AhImann and Lindblad, 1940; Wallén, 1948, 1949, 1959; Holmlund and Jansson, 1999), thereby producing a 100 year record of glacier mass balance and meteorology (Abisko Scientific Research Station, http:// www.linnea.com/ ans), an exceptional ice-front retreat record from 1909 to 1939 (cf. Karlén, 1973) and maps recording the glacier outline in 1908, 1920, 1925, 1926, 1928, 1939, 1943 and 1961. However, despite this historical interest, study of Kårsaglaciären has been neglected recently and it is no longer included in the regional massbalance measurements conducted out of Tarfala Research Station (personal communication from P. Jansson, 2010.

\section{METHODS}

A common-offset ground-penetrating radar (GPR) survey was carried out across the lower reaches of Kårsaglaciären in March 2009. This involved collecting a total of $3191 \mathrm{~m}$ of GPR data. These data constituted a main east-west centre line along the lower centre of the glacier, an east-west line along an upper (southern) 'bench' and four lines crossing the main centre line (Fig. 1). Data were collected continuously using a pulseEKKO Pro system towed behind a snowmobile. The GPR control unit was mounted on the snowmobile, while a purpose-built antenna sledge was towed approximately $6 \mathrm{~m}$ behind it. The antennas were fixed parallel to one another and transverse to the survey direction, thus minimizing offline reflections (cf. Murray and others, 2007). Data were collected while moving continuously over the central portion of the glacier tongue, at a centre frequency of $50 \mathrm{MHz}$ (Fig. 1). Real-time kinematic (RTK) differential GPS (DGPS) data were collected simultaneously via a Leica GPS500 to accurately locate the GPR on the glacier. The roving unit was mounted on the snowmobile, while the base station was located at a fixed point in the glacier forefield. In 2009 and 2010 we also made DGPS measurements of the snow surface elevation across the entire lower portion of Kårsaglaciären (Fig. 1).

The software packages ReflexW and Leica GeoOffice were used to process the GPR and DGPS data, respectively. For all GPR data, time zero was set before a filter was applied to remove low-frequency noise generated by the GPR system electronics. All data were then resampled to a uniform $0.5 \mathrm{~m}$ step size to account for variable sample spacing $(0.5 \mathrm{~m}$ was chosen as this is the recommended step size for $50 \mathrm{MHz}$ antennas). Data were then migrated using an FK algorithm before being bandpass-filtered with a pass band of $30-80 \mathrm{MHz}$. Finally, data were corrected topographically using the DGPS data, and two-way travel time was converted to ice thickness assuming a typical constant radar wave velocity of $0.168 \mathrm{~m} \mathrm{~ns}^{-1}$ (cf. Murray and others, 2007; King and others, 2008).

Dominant reflectors in the radar data (later interpreted to be the glacier surface and glacier bed) were then picked manually using ReflexW. For the surface, we picked the first break of the first energy arrival, which strictly speaking is a combination of the airwave and the ground wave. Separating the ground wave from the airwave was not possible 

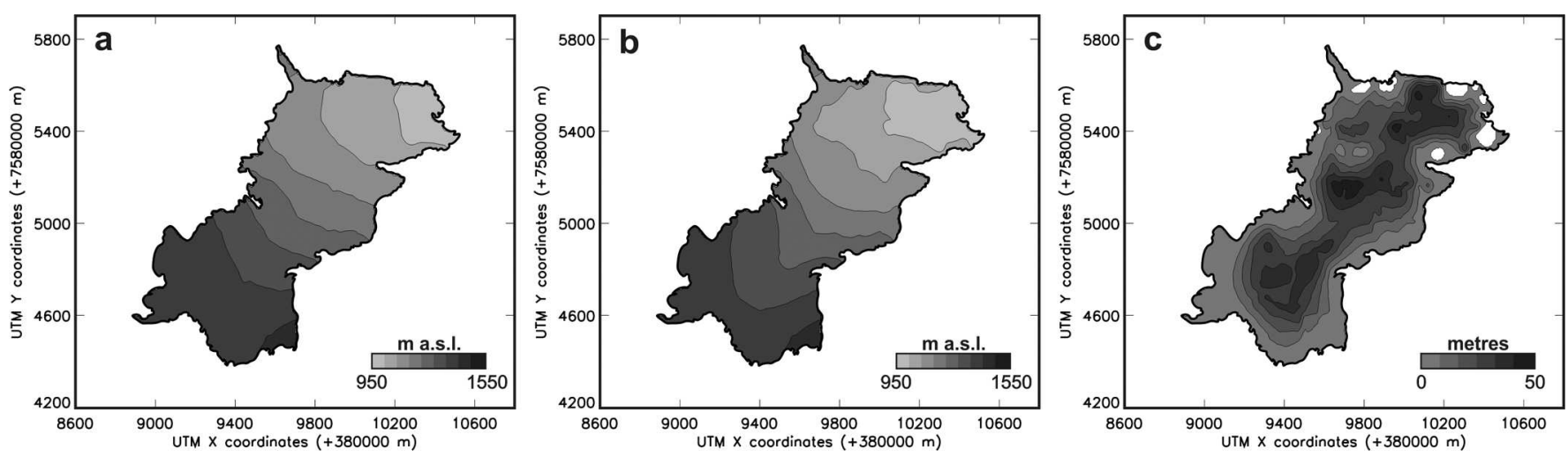

Fig. 2. (a) Surface DEM of Kårsaglaciären based on DGPS data collected in March 2010. (b) Bed DEM of Kårsaglaciären based on $50 \mathrm{MHz}$ GPR data collected in April 2009 and sparse ice-thickness data from 1992 (after Bodin, 1993). In the cases of the surface and bed, data were interpolated using a kriging routine within ArcGIS. (c) Ice thickness determined by subtracting bed elevations from surface elevations to give thickness measurements in March 2010. In some locations, ice thicknesses were negative (white areas near the northern margin and snout). These are discussed in the text.

because of interference between the two. The resulting processed radargrams were tested for internal consistency by checking the surface and bed elevations at crossover points between intersecting GPR lines. Surface elevation crossover errors were very small, with a mean error magnitude of just $\pm 0.07 \mathrm{~m}$. Bed crossover errors had a mean magnitude of $\pm 3.7 \mathrm{~m}$. However, this mean error is distorted by measurements at a single location (Fig. 1), where the discrepancy was $10.8 \mathrm{~m}$. Excluding this erroneous point, crossover errors are $\pm 1.4 \mathrm{~m}$. This smaller value is acceptable in bed error analyses of this nature.

Owing to topographical constraints, the uppermost basin could not be accessed safely, so we lack recent GPR data from this location. Instead we utilize ice-thickness data collected in spring 1992 (Bodin, 1993) using a Mark II echo sounder with a transmit frequency of $2-10 \mathrm{MHz}$. Bodin's (1993) receiver was an oscilloscope, and ice depth was calculated using trigonometry between the transmitter, bottom and receiver. Here we combine these 1992 data with our 2009 survey data to facilitate the creation of a bed digital elevation model (DEM) over the whole glacier. Clearly, there are limitations in doing this, due to the use of different frequencies, as well as poorer positional accuracy and sparser measurements in the older data. To determine bed elevations from the 1992 ice-thickness measurements we subtracted them from a digitized surface elevation map derived from aerial photography collected in 1991 by the National Land Survey of Sweden (C) Stockholm University). Where Bodin's (1993) bed elevation data coincide horizontally with our 2009 data, we compared the two in order to assess the relative accuracy of the two datasets and thus indicate the validity of combining them. Bed elevation agreement between the two datasets was assessed at locations where any of our data points fell within $10 \mathrm{~m}$ of Bodin's (1993) measurements. The mean magnitude of difference between the two datasets was $15.04 \mathrm{~m}$, but one of Bodin's points was responsible for much of this difference. By removing this point (designated erroneous by the presence of $>402009$ points within $10 \mathrm{~m}$ of this location and having a high degree of internal consistency), mean bed discrepancies were reduced to just $6.6 \mathrm{~m}$. Given that there are many potential sources of error in the older data of Bodin (1993), we considered this smaller error magnitude to be acceptable.
Ultimately, we therefore produced maps of surface elevation, bed elevation and ice thickness in 2010. Surface and bed DEMs were created by interpolating (using kriging) all data across the extent of the glacier before smoothing and resampling the output onto a $5 \mathrm{~m}$ grid (Fig. 2a and b). Ice thickness in 2010 was determined by subtracting the bed elevation grid from the ice surface grid (Fig. 2c). In a few locations, our map of ice thickness suggested the ice was of negative thickness. Clearly, this cannot be the case, so where the ice thickness was negative but of a magnitude less than the mean crossover error resulting from combining the two datasets $(6.6 \mathrm{~m})$ we set ice thickness to zero. This leaves a small number of areas of greater negative thickness, which are visible in Figure 2c as white areas located primarily at the snout and northern boundary of the glacier. The two largest of these areas near the snout are exactly where ice tunnels have collapsed, revealing portals (personal communication from P. Holmlund, 2010) and ice thickness was indeed close to zero.

\section{RESULTS AND ANALYSIS}

Figure 3 is an example of the data collected during our survey, showing the longest profile running west-east. This figure is typical of the radar data collected, in that there are two dominant reflectors, an upper surface reflection and a lower basal reflection, which are largely visible throughout. In Figure 3, the two reflectors merge at the snout $(\sim 850 \mathrm{~m}$ along transect) and here the basal reflector is slightly obscured by a zone of intense scattering of the GPR signal (Fig. 3). This zone appears to extend throughout the entire thickness of the snout and to end quite abruptly $\sim 650$ $700 \mathrm{~m}$ along transect. Such a zone of scattering is also identified in the lowermost cross-glacier line and in a small section of the southernmost isolated line. The basal reflector is partially obscured where these zones of scatter appear. In Figure 3, the basal reflector behind this zone of intense scattering drops in elevation and at the same time a substantial reflection-free zone is evident. This reflectionfree zone persists between $\sim 360$ and $680 \mathrm{~m}$ along transect. From $\sim 220$ to $360 \mathrm{~m}$ along transect, there is perhaps some sparse evidence of more scattering over a slightly raised area. Beyond this, the ice thins and scattering becomes very sparse again. Overall our GPR data are largely scatter-free 


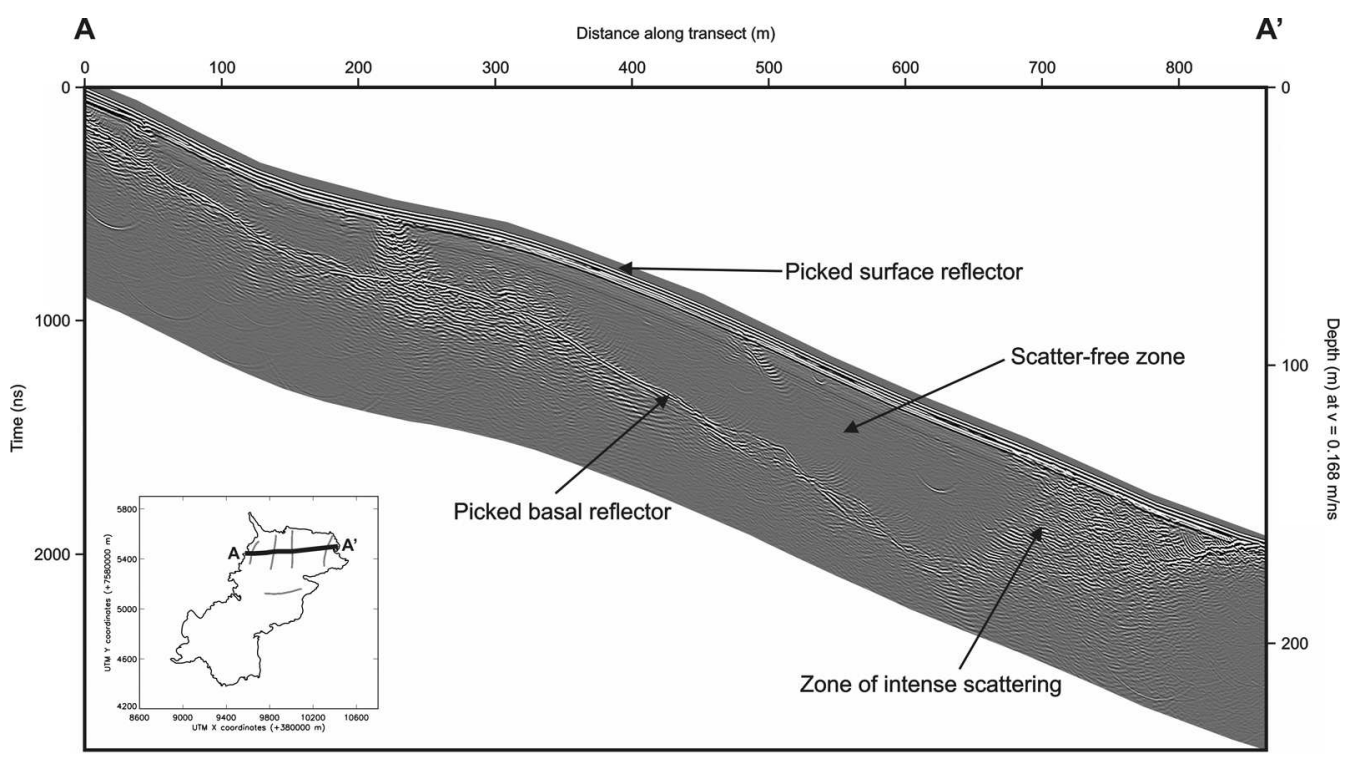

Fig. 3. Example processed GPR line along the centre of the main trunk (marked in black in inset). The glacier bed is clearly resolved, as is a zone of intense internal scattering very close to the glacier snout. Aside from this area, the image shows that much of the ice is largely scatter-free. Note that the line runs from high elevations in the west to low elevations in the east, i.e. A-A'. Flow direction is towards the right of the image.

and where scattering occurs it is made up of a series of individual point reflectors, which in unmigrated radar data appear as hyperbolae (Fig. 4).

We interpret the upper reflection as the ice surface and the lower basal reflection as the glacier bed. We interpret the area where the basal reflection drops away as being an overdeepening in the basal bedrock. The raised area is a bedrock bump.

Many of our radar data are interpreted as being free of internal scattering due to the presence of cold ice that does not contain liquid water. Thus there is minimal or no return of radar energy from within the ice. In contrast, the scattering zones in our data are similar to those observed within GPR data from glaciers in environments as diverse as the High Arctic and the European Alps. In these environments, GPR scatter zones are frequently attributed to the presence of warmer ice containing liquid water (Murray and others, 2007). This link between scattering and the presence of temperate ice has been clarified by comparing the radar-derived thermal structure with direct temperature measurements (e.g. Björnsson and others, 1996; Ødegård and others, 1997; Pettersson and others, 2003; Gusmeroli and others, 2010).

In order to ascertain the cause of the GPR scatters at Kårsaglaciären, we determined the GPR signal velocity at different depths by constructing idealized diffraction hyperbolae of known velocities and fitting them to the hyperbolae present in our GPR data (cf. Moore and others, 1999; Benjumea and others, 2003; Daniels, 2004; Navarro and others, 2005; Brandt and others, 2007; Murray and others, 2007). This fitting of hyperbolae is possible because: (1) the geometry of individual diffraction hyperbolae in commonoffset GPR surveys is a function of the velocity of electromagnetic energy; and (2) the GPR wave velocity varies depending on the nature of the material through which the energy travels (Murray and others, 2007). We used unmigrated data when fitting hyperbolae, because some of the processing steps that were followed to enable the glacier bed to be seen most clearly remove some of the higher-frequency scatters and because the process of migration collapses hyperbolae to their point source.

Figure $4 \mathrm{a}-\mathrm{c}$ show unmigrated sections without topographic correction where we identify intense internal scattering. In Figure $4 \mathrm{a}-\mathrm{c}$, numerous hyperbolae are indicated by white ellipses. We avoid showing the modelled hyperbolae as they would obscure the measured hyperbolae. The number tied to each ringed hyperbola in Figure 4 represents the velocity of each modelled hyperbola $\left(\mathrm{m} \mathrm{ns}^{-1}\right)$. In Figure 5, the hyperbolae identified in our data are plotted for each of the three transects that incorporate the zones of intense scattering (cf. Fig. 4). In each panel, we plot the velocity and depth of measured hyperbolae: the vast majority are associated with the zone of scattering in which we are interested, but a small number are also visible close to the glacier surface and from within other parts of the glacier not dominated by extensive scattering.

Our investigation of the internal GPR scatters within Kårsaglaciären firstly shows that the measured hyperbolae have velocities ranging from 0.130 to $0.220 \mathrm{~m} \mathrm{~ns}^{-1}$. Secondly, we identify that the hyperbolae velocity is related to their position within the glacier. Typical velocities of material found in glaciers are: for ice, $0.150-0.173 \mathrm{~m} \mathrm{~ns}^{-1}$; for snow, 0.212-0.245 $\mathrm{m} \mathrm{ns}^{-1}$; and for dry sedimentary material, $\sim 0.150 \mathrm{~m} \mathrm{~ns}^{-1}$ (after Daniels, 1996, 2004; Eisen and others, 2002, 2006; Brandt and others, 2007). The highest velocities we identify are associated with nearsurface hyperbolae and thus are highly likely to be associated with scatters within surface snow. Hyperbolae identified in the middle parts of the glacier have velocities ranging from $\sim 0.163$ to $0.170 \mathrm{~m} \mathrm{~ns}^{-1}$ and thus we attribute these to typical glacier ice. We also identify velocities in the intense scattering zones ranging from 0.130 to $0.150 \mathrm{~m} \mathrm{~ns}^{-1}$. We interpret these hyperbolae as indicating the presence of either dry sediments or warmer temperate ice.

Since the GPR velocities that we identify associated with the intense scattering zone of hyperbolae near the glacier snout fit well with those reported in the literature for temperate glacier ice (Daniels, 1996, 2004; Eisen and others, 

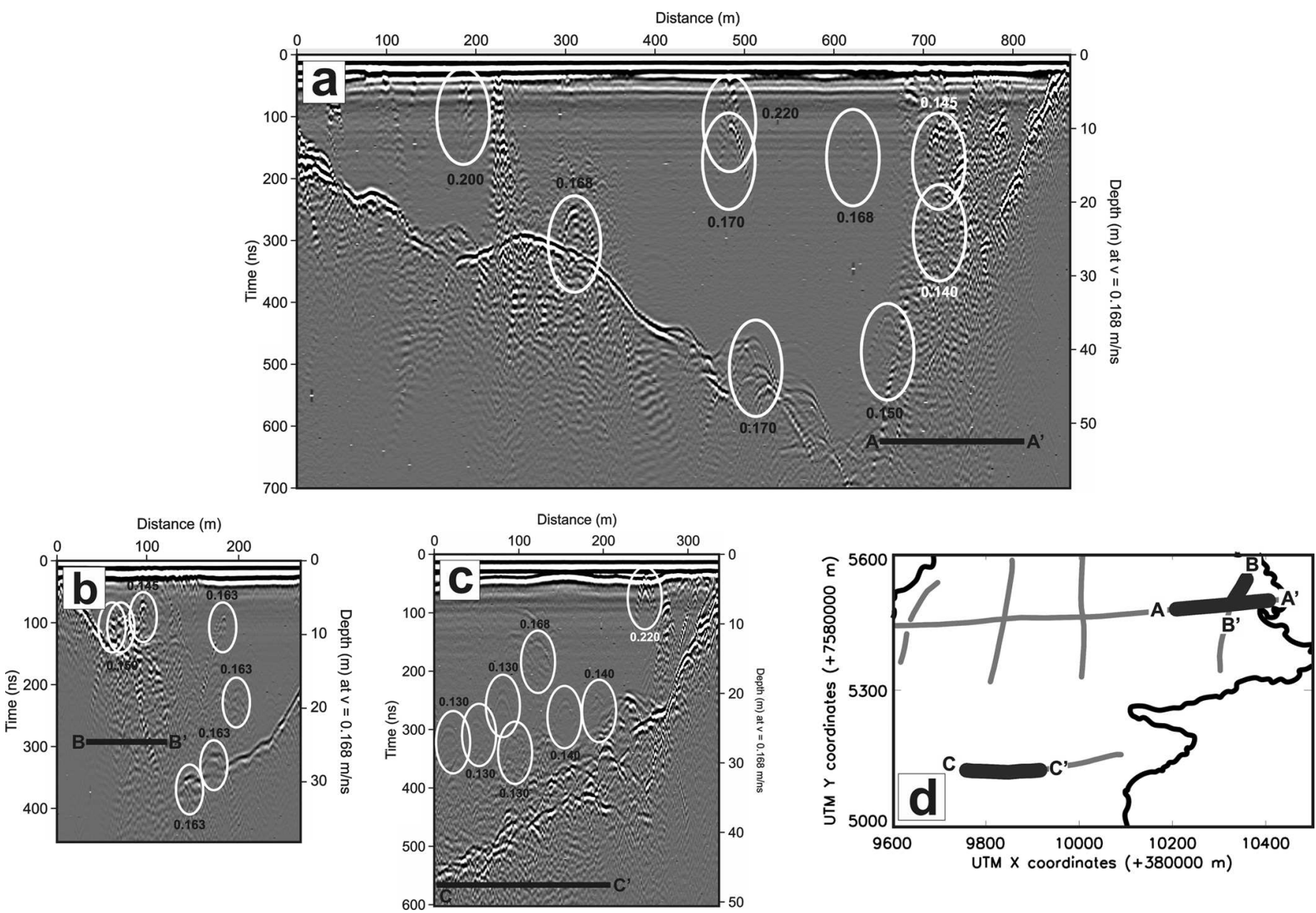

Fig. 4. (a-c) 2009 GPR radargrams where intense internal scattering is observed. In all cases, no topographic correction, filtering or migration has been carried out. (a) West-east running GPR line. The radargram runs the entire length of the east-west line shown in light grey in (d). The section $A-A^{\prime}$ (marked in (a) with the horizontal black line) is highlighted in dark grey in (d). This is the section where intense internal scattering is observed. The white ellipses indicate examples of hyperbolae in the data created by assumed point reflectors, visible in unmigrated data. Theoretical hyperbolae were matched to these visible hyperbolae to determine radar wave propagation velocities (associated numbers in white or black, $\mathrm{m} \mathrm{ns}^{-1}$ ). Hyperbolae are prominent in these areas of intense scattering, but also elsewhere in the radargram. They are discussed fully in the text. (b) The radargram from the northwest line in the lowest portion of the glacier; the section marked with the horizontal black line and labelled B-B' is highlighted in (d) as before. (c) The west-east running radargram from the southernmost part of the glacier.
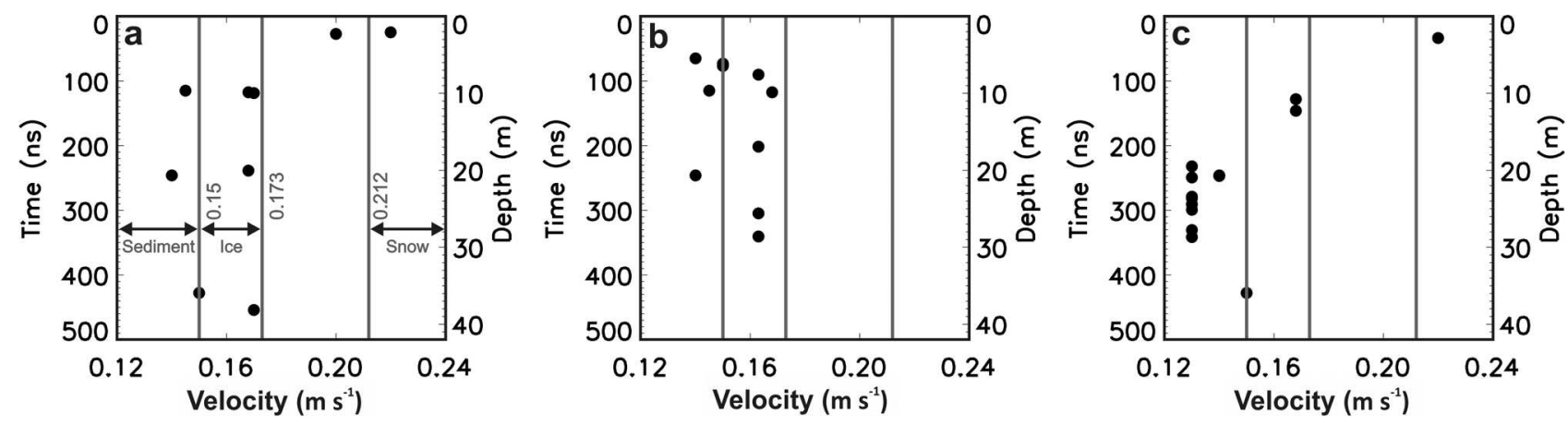

Fig. 5. (a-c) Plots of radio-wave velocity against time and depth in the three radar lines shown in Figure 4a, b and c, respectively. Each point represents the location of a hyperbola to which theoretical hyperbolae of known velocities are fitted. Vertical grey lines indicate typical velocities associated with certain materials. In (a) these are annotated, such that the typical maximum velocity of radio waves in dry sedimentary material is $\sim 0.15 \mathrm{~m} \mathrm{~ns}^{-1}$; typical velocities of radio waves in ice are $0.150-0.173 \mathrm{~m} \mathrm{~ns}^{-1}$, and typical velocities in snow are 0.212-0.245 $\mathrm{m} \mathrm{ns}^{-1}$ (after Daniels, 1996, 2004; Eisen and others, 2002, 2006; Brandt and others, 2007). The same vertical indicators are present in (b) and (c), but there are no labels, so as to avoid clutter in these parts of the figure. 

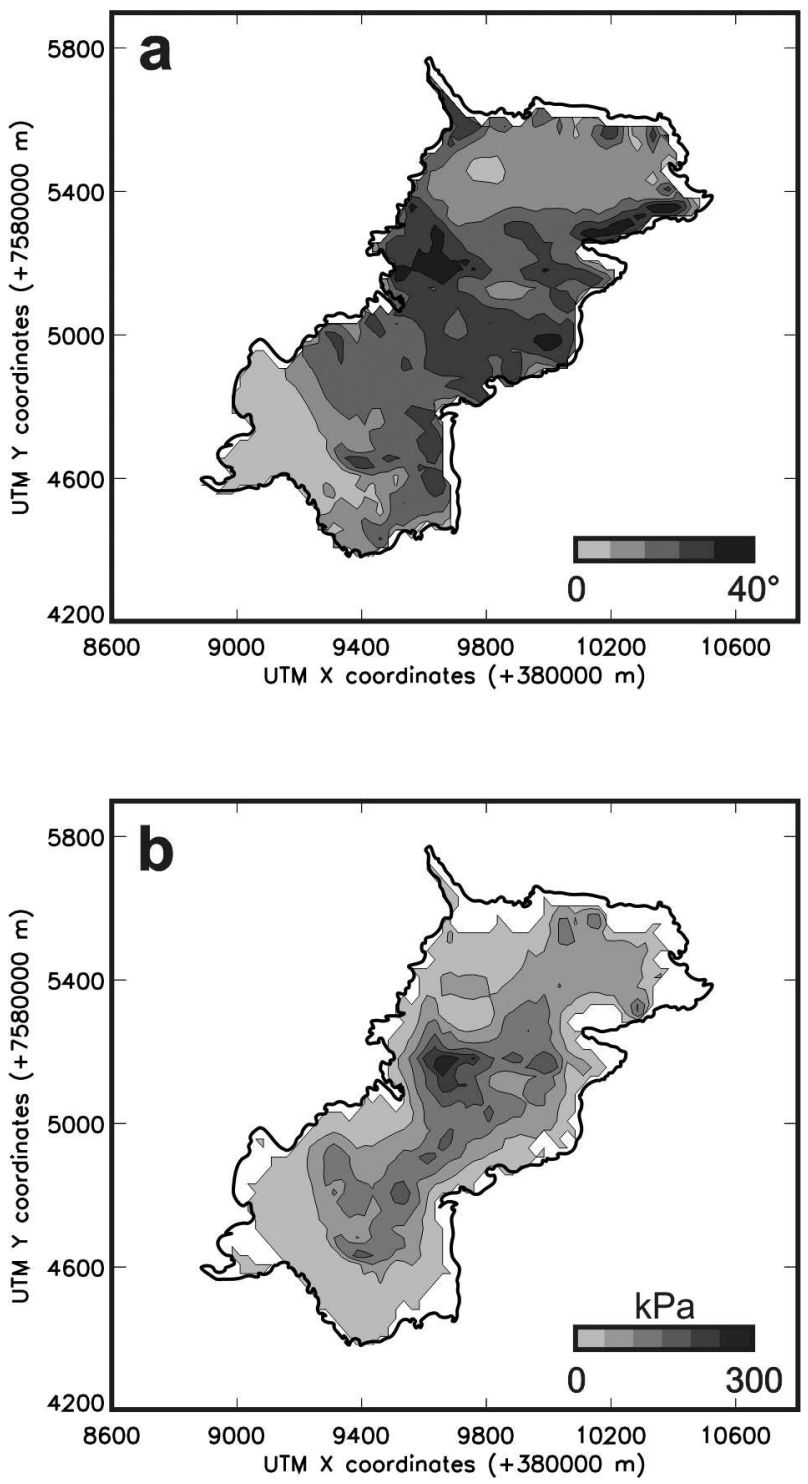

Fig. 6. (a) Surface slope $\left(^{\circ}\right)$ across Kårsaglaciären. Slope is derived from raw elevation data, but is determined over gridcells of $25 \mathrm{~m}$ (equal to approximately half the maximum ice thickness), in order to remove very short-scale slope variations. (b) Driving stress across the glacier $(\mathrm{kPa})$. Both driving stress and surface slope are not calculated close to ice margins.

2002, 2006; Brandt and others, 2007), we are confident that we can interpret these zones of scattering as being indicative of temperate ice, i.e. ice containing water, either with or without englacial sediments. We therefore propose that part of the ablation zone of Kårsaglaciären contains temperate ice and thus that it is presently polythermal.

\section{DISCUSSION}

\section{Glacier geometry}

Our investigations indicate that Kårsaglaciären is presently slightly less than $2 \mathrm{~km}$ in length, covers a surface area of $0.85 \mathrm{~km}^{2}$ and has an altitudinal range of $\sim 983-1500 \mathrm{~m}$ a.s.l. The lower- and uppermost parts are relatively flat, with surface slopes of less than $\sim 10^{\circ}$, while the central portion is steeper, with surface slopes of $\sim 25-40^{\circ}$ (Fig. 6a). Presently, the glacier has an overall volume of $\sim 0.0178 \mathrm{~km}^{3}$ and a maximum thickness of $\sim 56 \mathrm{~m}$. Bodin (1993) reported that in
1992 the glacier covered an area of $\sim 1.2 \mathrm{~km}^{2}$, had a maximum thickness of $\sim 70 \mathrm{~m}$ and a total volume of $0.04 \mathrm{~km}^{3}$. Therefore, over the 17 years between the two studies, the glacier area has shrunk by $>29 \%$, the volume by $>55 \%$ and the thickness by $20 \%$ (expressed as a proportion of the 1992 values).

The central steep area coincides with one of three areas of thickest ice running in a linked chain along the central line of the glacier (Fig. 2c). Interestingly, the thick areas are not associated with distinct topographic overdeepenings. Nevertheless, there is a central trough running along the glacier centre and it is clear that ice flow would be focused along this trajectory. This is reinforced by calculations of driving stress (Fig. 6b), which is calculated as:

$$
\tau_{\mathrm{d}}=\rho_{\mathrm{i}} g h \sin \alpha,
$$

where $\tau_{\mathrm{d}}$ is the driving stress (Pa), $\rho_{\mathrm{i}}$ is the density of ice $\left(917 \mathrm{~kg} \mathrm{~m}^{-3}\right), g$ is acceleration due to gravity $\left(9.81 \mathrm{~m} \mathrm{~s}^{-2}\right), h$ is ice thickness and $\alpha$ is the surface slope in degrees (e.g. Van der Veen and Whillans, 1989). Figure 6b clearly shows elevated driving stress along the centre of the glacier, coinciding with the area of thickest ice, reaching a clear maximum of $\sim 295 \mathrm{kPa}$ in the glacier's centre where surface slopes are also greatest.

\section{Thermal regime}

Our interpretation of temperate ice within the ablation area of Kårsaglaciären is a surprise and refutes our hypothesis that a small Arctic glacier will have a cold ablation area. Murray and others (2000) stated that glaciers less than $\sim 100 \mathrm{~m}$ thick tend to be cold, so we question how temperate ice can exist in this location within Kårsaglaciären. We acknowledge the possibility that (part of) the accumulation area might also be temperate in a similar way to Storglaciären, but we have no data from this region.

Storglaciären is located at $67.9^{\circ} \mathrm{N}, 18.57^{\circ} \mathrm{E}$ and thus is slightly further south than Kårsaglaciären. It is longer than Kårsaglaciären at $3.12 \mathrm{~km}$ as opposed to $\sim 2 \mathrm{~km}$ and is found at a slightly higher altitude of 1130-1750 m a.s.l. compared with 983-1500 ma.s.I. It is also substantially thicker than Kårsaglaciären, attaining a maximum thickness of $250 \mathrm{~m}$. It has a polythermal regime in which $\sim 85 \%$ of the glacier is temperate, with a cold surface layer in the ablation area (Pettersson and others, 2003; Gusmeroli and others, 2010). By contrast, Kårsaglaciären's maximum thickness is just $\sim 56 \mathrm{~m}$.

At Kårsaglaciären, temperate ice at the snout of an otherwise cold glacier conforms to a type B polythermal glacier as summarized by Pettersson (2004). However, the structure we envisage here is more complex, involving a much smaller temperate zone in the snout, with a main cold body in the upper to mid-ablation area and the possibility of a temperate area in the accumulation zone. It is important to note that this structure is markedly different from that of Storglaciären, which conforms more closely to a type E polythermal glacier (after Pettersson, 2004), in which the glacier is largely temperate with only a thin cold surface layer in the ablation zone.

The difference between the thermal structure of Kårsaglaciären and Storglaciären can be explained by considering the mechanisms responsible for producing and modifying that thermal structure. At Storglaciären, melting of surface snow and its percolation into a porous firn aquifer leads to the generation of substantial heat and of new temperate ice 
when this water refreezes (Pettersson and others, 2007; Gusmeroli and others, 2010). This temperate body is then maintained by the advection of temperate ice throughout the glacier, and the overall ice thickness. While we might assume similar melting takes place in the accumulation area of Kårsaglaciären, it is clear from the largely cold ablation zone that any advected temperate ice cannot be sustained, possibly as a consequence of thin ice and the role of the winter cold wave outlined previously. We must therefore seek another explanation for the small area of temperate ice in the snout. The existence of temperate ice is most often attributed to enhanced strain heating (Blatter and Hutter, 1991; Pettersson, 2004; Benn and Evans, 2010) and thus to driving stress. Kårsaglaciären presently generates driving stresses up to $\sim 295 \mathrm{kPa}$ (Fig. 6b). These driving stresses, although high, are limited spatially to the central steep and thick portion of the glacier, and are evidenced by the strain response of brittle failure and thus severe surface crevassing visible here. In the lowermost part of Kårsaglaciären where slopes are shallow (Fig. 6a) and the ice is thin (Fig. 2c), driving stress is low (Fig. 6b). Thus we suggest that strain heating is not a viable mechanism to produce melting and temperate ice formation in the snout of Kårsaglaciären.

The only other widely cited mechanisms for producing temperate ice in this location are via heating due to a geothermal heat flux, meltwater refreezing and heat conduction and advection from the surface (Blatter and Hutter, 1991; Pettersson, 2004; Pettersson and others, 2007; Benn and Evans, 2010). If geothermal fluxes were high at Kårsaglaciären then we would expect to see temperate ice over a much wider area, so we discount this mechanism. Temperate ice could be formed within the snout of Kårsaglaciären by meltwater refreezing. There are two small meltwater portals and some crevasses that could act as access points for water to englacial locations. However, we believe that the two portals and these few crevasses are not sufficiently widespread to explain the spatial pattern of scattering within our GPR data. Furthermore, crevasses are most likely to contribute to cooling of ice by facilitating penetration of the winter cold wave to greater depth. So, unlike Storglaciären, the ablation zone of Kårsaglaciären is cold throughout, apart from the small patch in the snout, and this present temperate ice zone within Kårsaglaciären cannot be explained using prevailing hypotheses of the mechanisms of temperate ice formation and of the controls on polythermal glacier structure. Therefore it seems highly unlikely that the ablation area of Kårsaglaciären is actively polythermal, i.e. that its current geometry and thickness are not able to maintain the polythermal structure that we observe.

We therefore propose a conceptual model (Fig. 7) in which the present internal structure of Kårsaglaciären is a remnant of a past thermal state. When Kårsaglaciären was more extensive and thicker (Schytt, 1959), we believe that it was actively polythermal in the way that Storglaciären currently is (cf. Pettersson, 2004). However, substantial mass loss in recent decades (e.g. 20\% of ice thickness since 1992; Bodin, 1993) means that it can no longer actively sustain a polythermal structure in the ablation zone, so the temperate ice found in the lower glacier is a remnant of a previously more extensive temperate core (Fig. 7). In this sense Karsaglaciären might represent a future analogue for Storglaciären-type polythermal glaciers if extensive thinning continues. Under a warming climate, a Storglaciären-type polythermal glacier might thin and although local climatic
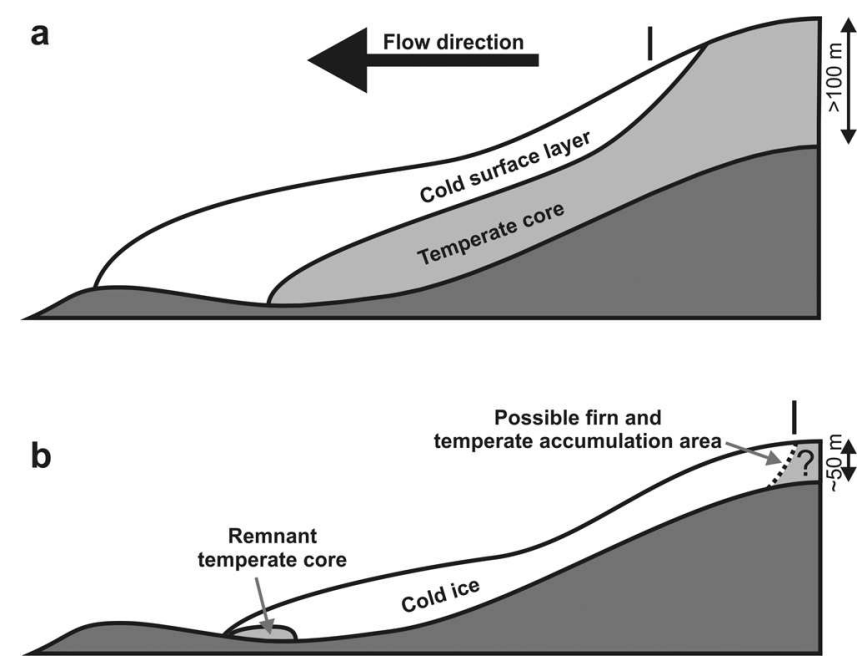

Fig. 7. Conceptual model of the structure of Kårsaglaciären (a) at some point in the past and (b) at present. The black vertical line indicates the location of the equilibrium line. Previously, the glacier was thicker and could sustain a polythermal structure. Here it is shown to be a type E polythermal glacier (after Pettersson, 2004), otherwise known as a type $\mathrm{C}$ polythermal glacier (after Blatter and Hutter, 1991). Subsequent retreat and thinning has resulted in deeper penetration of the winter cold wave, so it is no longer possible to sustain a temperate core. Thus, the glacier is largely cold, but a small area of remnant temperate ice remains in the snout - the legacy of the glacier's previous polythermal structure. A potential temperate accumulation area as a result of refreezing of water in a porous firn layer is also indicated. The accumulation area could be entirely temperate, partially temperate or entirely cold. We do not know the nature of the thermal regime here, hence the indicated uncertainty. Nevertheless, we propose that, in time, the glacier will eventually become cold throughout.

conditions enable melting and refreezing in a porous accumulation area to continue, thinning of the ablation area to a critical thickness would mean it would begin to turn cold as with Kårsaglaciären. This leads us to suggest that in the future the present volume of temperate ice will shrink and cool further, so that ultimately Kårsaglaciären may become fully cold.

Significantly, our conceptual model is very different from the changes currently being observed on Storglaciären, where a cold surface layer has thinned in recent years due to an increase in winter temperatures (Pettersson and others, 2007). While Storglaciären is losing its cold surface layer in the ablation zone and becoming warmer, we propose Kårsaglaciären is losing its zone of temperate ice in the ablation zone and thus becoming colder. This raises the possibility of a complicated evolutionary split, in which some polythermal glaciers may evolve towards a fully temperate thermal ablation zone (Storglaciären-type) while others may evolve towards a fully cold ablation zone (Kårsaglaciärentype), depending on ice thickness. It also suggests that, in time, a Storglaciären-type glacier might subsequently become a Kårsaglaciären-type glacier if it thins sufficiently.

\section{CONCLUSIONS}

Kårsaglaciären presently has a maximum ice thickness of $\sim 56 \mathrm{~m}$ and covers an area of $0.855 \mathrm{~km}^{2}$. It is representative of most Arctic glaciers; $64.2 \%$ of all Arctic glaciers are 
$<2 \mathrm{~km}^{2}$ in area and $\sim 51 \%$ are $<1 \mathrm{~km}^{2}$ (http://nsidc.org/data/ g01130.html). We have presented the first models of the present-day ice surface and ice thickness and of the subglacial bed topography of Kårsaglaciären. We have also established the contemporary basal conditions and internal structure of Kårsaglaciären and identified a zone of temperate ice near the glacier snout. This zone of temperate ice in an otherwise cold-based glacier demonstrates that Kårsaglaciären is presently polythermal. We suggest that this polythermal regime is not active, i.e. it is a remnant of past glacier geometry and past climate. We propose that as Kårsaglaciären thinned, its warm 'core' became unsustainable and decreased in volume. We presume that with time it will lose more volume and eventually disappear. In this way Kårsaglaciären will have transformed from a fully polythermal glacier to a glacier either with a cold thermal regime or a fully cold ablation zone. Our identification of a remnant temperate core indicates that there is a lag in the evolution of the thermal structure of a glacier, causing it to be out of synch with current geometry and climate. It seems probable that many other small Arctic polythermal glaciers could become fully cold (in the ablation zone) due to thinning below some threshold thickness with climate change. Conversely, a thicker polythermal glacier might maintain its temperate ablation zone and evolve towards a fully temperate state, with the possibility that subsequent thinning might force such a glacier along a pathway similar to Kårsaglaciären. If the ablation area of a glacier reaches a fully cold state from a previous polythermal condition, the dynamics and hydrology of that glacier, and ultimately the glacier massbalance response, will alter. Consequently, some small Arctic glaciers may not sustain present meltwater contributions to sea-level rise. Further work is urgently required to ascertain more fully the thermal structure of small Arctic glaciers, the controls on the thermal regime and the likely evolution of the thermal regime in response to climate change, glacier mass balance and glacier dynamics.

\section{ACKNOWLEDGEMENTS}

D.M. Rippin and J.L. Carrivick are recipients of the 2010 Royal Geographical Society (RGS) Peter Fleming award. J.L. Carrivick was awarded an Access to Abisko Naturvetenskapliga Station (ATANS) grant, a Geographical Fieldwork Grant funded by the Ralph Brown Memorial Trust (administered through the RGS) and a Quaternary Research Association (QRA) research fund grant for this project. The automatic weather station (AWS) was funded by the School of Geography, University of Leeds, and installed with help from L. Brown and D. Hannah. The GPR was borrowed from the Department of Geography, University of Hull, UK. Fieldwork in 2009 and 2010 was financially assisted by the School of Geography, University of Leeds. We thank P. Jansson and P. Holmlund for insightful comments on an early draft of the manuscript and for their thorough support of our work in terms of data and advice; B. Barrett for his insightful comments; D. Carrivick for competent and diligent assistance with fieldwork in 2009 and 2010; C. Plant and C. Mellor for downloading the AWS; and all the ANS staff for their excellent professional help and friendly advice. Finally, we thank A. Gusmeroli, an anonymous referee and the editor J. Woodward for assistance in improving the manuscript.

\section{REFERENCES}

Ahlmann, H.W. and T. Lindblad. 1940. Die Grössenveränderungen des Karsajökels in Schwedisch-Lappland während der Jahre 1909-1939. Geogr. Ann., 22(1-2), 80-94.

Ahlmann, H.W. and O. Tryselius. 1929. Der Kårsa-Gletscher in Schwedisch-Lappland. Geogr. Ann., 11A, 1-32.

Arendt, A.A., K.A. Echelmeyer, W.D. Harrison, C.S. Lingle and V.B. Valentine. 2002. Rapid wastage of Alaska glaciers and their contribution to rising sea level. Science, 297(5580), 382-386.

Aschwanden, A. and H. Blatter. 2005. Meltwater production due to strain heating in Storglaciären, Sweden. J. Geophys. Res., 110(F4), F04024. (10.1029/2005JF000328.)

Bamber, J.L. 1989. Ice/bed interface and englacial properties of Svalbard ice masses deduced from airborne radio echosounding data. J. Glaciol., 35(119), 30-37.

Bates, B., Z.W. Kundzewicz, S. Wu and J. Palutikof, eds. 2008. Climate change and water. Geneva, Intergovernmental Panel on Climate Change. (Technical Paper 6.)

Benjumea, B., Yu.Ya. Macheret, F.J. Navarro and T. Teixidó. 2003. Estimation of water content in a temperate glacier from radar and seismic sounding data. Ann. Glaciol., 37, 317-324.

Benn, D.I. and D.J.A. Evans. 2010. Glaciers and glaciation. Second edition. London, Hodder Education.

Bennett, M.R. and N.F. Glasser. 2009. Glacial geology. Second edition. Oxford, Wiley-Blackwell.

Bingham, R.G., P.W. Nienow, M.J. Sharp and L. Copland. 2006. Hydrology and dynamics of a polythermal (mostly cold) High Arctic glacier. Earth Surf. Process. Landf., 31(12), 1463-1479.

Björnsson, H. and 6 others. 1996. The thermal regime of sub-polar glaciers mapped by multi-frequency radio-echo sounding. J. Glaciol., 42(140), 23-32.

Blatter, H. and K. Hutter. 1991. Polythermal conditions in Arctic glaciers. J. Glaciol., 37(126), 261-269.

Bodin, A. 1993. Physical properties of the Kårsa glacier, Swedish Lapland. Stockholm, University of Stockholm. Department of Physical Geography. (Research Report 17.)

Brandt, O., K. Langley, J. Kohler and S.-E. Hamran. 2007. Detection of buried ice and sediment layers in permafrost using multifrequency Ground Penetrating Radar: a case examination on Svalbard. Remote Sens. Environ., 111(2-3), 212-227.

Carrivick, J.L. and T.R. Brewer. 2004. Improving local estimations and regional trends of glacier equilibrium line altitudes. Geogr. Ann., 86A(1), 67-79.

Daniels, D.J. 1996. Surface-penetrating radar. London, Institution of Electrical Engineers. (Radar, Sonar, Navigation and Avionics Series 6.)

Daniels, D.J. 2004. Ground penetrating radar. Second edition. London, Institution of Electrical Engineers. (IET Radar, Sonar, Navigation and Avionics Series 15.)

Dowdeswell, J.A. and 10 others. 1997. The mass balance of circum-Arctic glaciers and recent climate change. Quat. Res., $48(1), 1-14$

Eisen, O., U. Nixdorf, F. Wilhelms and H. Miller. 2002. Electromagnetic wave speed in polar ice: validation of the commonmidpoint technique with high-resolution dielectric-profiling and $\gamma$-density measurements. Ann. Glaciol., 34, 150-156.

Eisen, O., F. Wilhelms, D. Steinhage and J. Schwander. 2006. Improved method to determine radio-echo sounding reflector depths from ice-core profiles of permittivity and conductivity. J. Glaciol., 52(177), 299-310.

Fischer, U.H. and G.K.C. Clarke. 2001. Review of subglacial hydromechanical coupling: Trapridge Glacier, Yukon Territory, Canada. Quat. Int., 86(1), 29-43.

Gusmeroli, A., T. Murray, P. Jansson, R. Pettersson, A. Aschwanden and A.D. Booth. 2010. Vertical distribution of water within the polythermal Storglaciären, Sweden. J. Geophys. Res., 115(F4), F04002. (10.1029/2009JF001539.)

Holmlund, P. and M. Eriksson. 1989. The cold surface layer on Storglaciären. Geogr. Ann., Ser. A, 71(3-4), 241-244. 
Holmlund, P. and P. Jansson. 1999. The Tarfala mass balance programme. Geogr. Ann., 81A(4), 621-631.

Hutter, K., H. Blatter and M. Funk. 1988. A model computation of moisture content in polythermal glaciers. J. Geophys. Res., 93(B10), 12,205-12,214.

Karlén, W. 1973. Holocene glacier and climatic variations, Kebnekaise mountains, Swedish Lapland. Geogr. Ann., 55A(1), $29-63$.

King, E.C., A.M. Smith, T. Murray and G.W. Stuart. 2008. Glacier-bed characteristics of midtre Lovénbreen, Svalbard, from high-resolution seismic and radar surveying. J. Glaciol., 54(184), 145-156.

Moore, J.C. and 8 others. 1999. High-resolution hydrothermal structure of Hansbreen, Spitsbergen, mapped by ground-penetrating radar. J. Glaciol., 45(151), 524-532.

Munro, D.S. 2000. Progress in glacier hydrology: a Canadian perspective. Hydrol. Process., 14(9), 1627-1640.

Murray, T. and 6 others. 2000. Glacier surge propagation by thermal evolution at the bed. J. Geophys. Res., 105(B6), 13,491-13,507.

Murray, T., A. Booth and D.M. Rippin. 2007. Water-content of glacier-ice: limitations on estimates from velocity analysis of surface ground-penetrating radar surveys. J. Environ. Eng. Geophys., 12(1), 87-99.

Navarro, F.J., Yu.Ya. Macheret and B. Benjumea. 2005. Application of radar and seismic methods for the investigation of temperate glaciers. J. Appl. Geophys., 57(3), 193-211.

Ødegård, R.S., J.O. Hagen and S.E. Hamran. 1997. Comparison of radio-echo sounding $(30-1000 \mathrm{MHz})$ and high-resolution borehole-temperature measurements at Finsterwalderbreen, southern Spitsbergen, Svalbard. Ann. Glaciol., 24, 262-267.

Paterson, W.S.B. 1994. The physics of glaciers. Third edition. Oxford, etc., Elsevier.

Pettersson, R. 2004. Dynamics of the cold surface layer of polythermal Storglaciären, Sweden. (PhD thesis, University of Stockholm.)

Pettersson, R., P. Jansson and P. Holmlund. 2003. Cold surface layer thinning on Storglaciären, Sweden, observed by repeated ground penetrating radar surveys. J. Geophys. Res., 108(F1), 6004. (10.1029/2003JF000024.)

Pettersson, R., P. Jansson and H. Blatter. 2004. Spatial variability in water content at the cold-temperate transition surface of the polythermal Storglaciären, Sweden. J. Geophys. Res., 109(F2), F02009. (10.1029/2003JF000110.)

Pettersson, R., P. Jansson, H. Huwald and H. Blatter. 2007. Spatial pattern and stability of the cold surface layer of Storglaciären, Sweden. J. Glaciol., 53(180), 99-109.
Prowse, T.D. 1990. Northern hydrology: an overview. In Prowse, T.D. and C.S.L. Ommanney, eds. Northern hydrology: Canadian perspectives. Saskatoon, Sask., Environment Canada. National Hydrology Research Institute. (NHRI Science Report 1.)

Radić, V. and R. Hock. 2011. Regionally differentiated contribution of mountain glaciers and ice caps to future sea-level rise. Nature Geosci., 4(2), 91-94.

Raper, S.C.B. and R.J. Braithwaite. 2006. Low sea level rise projections from mountain glaciers and icecaps under global warming. Nature, 439(7074), 311-313.

Rippin, D.M. 2002. The hydrology and dynamics of polythermal glaciers: Midre Lovénbreen, Svalbard. (PhD thesis, University of Cambridge.)

Rippin, D., I. Willis and N. Arnold. 2005. Seasonal patterns of velocity and strain across the tongue of the polythermal glacier midre Lovénbreen, Svalbard. Ann. Glaciol., 42, 445-453.

Schytt, V. 1959. The glaciers of the Kebnekajse-Massif. Geogr. Ann., 41(4), 213-227.

Schytt, V. 1969. Some comments on glacier surges in eastern Svalbard. Can. J. Earth Sci., 6(4), 867-873.

Sund, M. and T. Eiken. 2004. Quiescent-phase dynamics and surge history of a polythermal glacier: Hessbreen, Svalbard. J. Glaciol., 50(171), 547-555.

Svenonius, F.V. 1890. Ett besök vid Kårsajökeln. Svenska Turistföreningens Årsskrift, 115-127.

Svenonius, F.V. 1910. Die Gletscher Schwedens im Jahre 1908. Stockholm, Norsted \& Söner. (Sveriges Geologiska Undersökning 5.)

Sverdrup, H.U. 1935. The temperature of the firn on Isachsen's Plateau, and general conclusions regarding the temperature of the glaciers on West-Spitzbergen. Geogr. Ann., 17(1-2), 53-88.

Van der Veen, C.J. and I.M. Whillans. 1989. Force budget: I. Theory and numerical methods. J. Glaciol., 35(119), 53-60.

Wallén, C.C. 1948. Glacial-meteorological investigations on the Kårsa glacier in Swedish Lappland. Geogr. Ann., 30(3-4), 451-672.

Wallén, C.C. 1949. Shrinkage of the Karsa Glacier and its probable meteorological causes. Geogr. Ann., 31(1-2), 275-291.

Wallén, C.C. 1959. The Kårsa Glacier and its relation to the climate of the Torne Träsk region. Geogr. Ann., 41(4), 236-244.

Waller, R.I. 2001. The influence of basal processes on the dynamic behaviour of cold-based glaciers. Quat. Int., 86(1), $117-128$.

MS received 13 October 2010 and accepted in revised form 28 June 2011 